\title{
The false lumen: Not a forgotten problem
}

\author{
Chun Wang, MD, $\mathrm{PhD}$, and Tianxiang Gu, $\mathrm{MD}, \mathrm{PhD}$
}

\author{
From the Department of Cardiac Surgery, The First Hospital of China Medical University, Shenyang, China. \\ Disclosures: Authors have nothing to disclose with regard to commercial support. \\ Received for publication April 12, 2016; accepted for publication April 14, 2016; available ahead of print May 20 , \\ 2016. \\ Address for reprints: Tianxiang Gu, MD, PhD, Department of Cardiac Surgery, The First Hospital of China Med- \\ ical University, 155 Nanjing Bei St, Heping District, Shenyang 110001, China (E-mail: cmugtx@ sina.com). \\ J Thorac Cardiovasc Surg 2016;152:e45 \\ $0022-5223 / \$ 36.00$ \\ Copyright (c) 2016 by The American Association for Thoracic Surgery \\ http://dx.doi.org/10.1016/j.jtcvs.2016.04.043
}

Aortic dissection is a strong indication for emergent intervention, open surgery, or thoracic endovascular aortic repair (TEVAR), which has advanced quickly in recent years. With the continuing progress in surgical and interventional techniques, anesthesia, cardiopulmonary bypass, and intensive care, the mortality of aortic dissection is declining, and short-term outcomes are becoming more satisfactory. Nonetheless, false lumen patency and the location of the most-dilated aortic segment at the distal arch have been identified as independent risk factors for poor outcome in patients undergoing type B aortic dissection and those undergoing type A aortic dissection after ascending aorta surgery. 1 ,

Song and colleagues ${ }^{3}$ conducted an eloquent study examining the long-term natural course of descending aorta dilation after acute aortic dissection. The initial false lumen diameter at the upper descending thoracic aorta was identified as an independent predictor of late aneurysm. An initial false lumen diameter at the upper descending thoracic aorta of $>22 \mathrm{~mm}$ predicted late aneurysm with a sensitivity of $100 \%$ and a specificity of $76 \%$. Compared with patients with a smaller initial upper descending thoracic aorta false lumen diameter, those with an initial diameter of $>22 \mathrm{~mm}$ had a higher rate of aortic dilation and a higher incidence of clinical events, including development of aortic aneurysm and death.

A large false lumen diameter can serve as a single variable determining late aneurysmal change and poor clinical prognosis in patients with type B aortic dissection those with type A aortic dissection after ascending aorta surgery. Because of the surgical risk and the lack of special endovascular technique, how to deal with the residual large false lumen presents a clinical dilemma and challenge. In this issue of the Journal, Saitoh and colleagues ${ }^{4}$ discuss an alternative option. The patient underwent ascending aorta replacement for type A dissection before 7 years and underwent debranching TEVAR for residual dissection from the aortic arch to the distal aorta and dilation of the thoracic descending aorta. At 4 months after the TEVAR, a custommade false lumen occluder was implanted into the false lumen. A follow-up computed tomography scan at 9 months

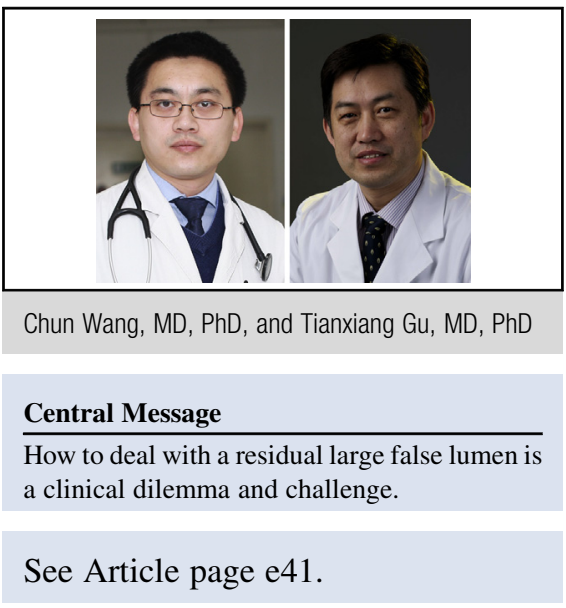

after occluder implantation showed remodeling of the thoracic descending aorta and significant shrinking of the false lumen.

This was a good attempt, and the authors also showed that eliminating the false lumen can be beneficial. Consistent with this idea, use of the candy-plug technique using an Excluder aortic extender for distal occlusion of a large false lumen aneurysm in chronic aortic dissection and an Amplatzer Vascular Plug II as a sealing button to obliterate the false lumen has been reported recently. ${ }^{5,6}$ In the future, more techniques and devices will be developed, but several factor should always be taken into consideration, including the type and timing of the intervention, patient selection, and outcomes. Attempting to eliminate tears and reentries starting at the beginning of the intervention may improve the prognosis.

\section{References}

1. Bernard Y, Zimmermann H, Chocron S, Litzler JF, Kastler B, Etievent JP, et al False lumen patency as a predictor of late outcome in aortic dissection. Am J Cardiol. 2001;87:1378-82.

2. Akutsu K, Nejima J, Kiuchi K, Sasaki K, Ochi M, Tanaka K, et al. Effects of the patent false lumen on the long-term outcome of type B acute aortic dissection. Eur J Cardiothorac Surg. 2004;26:359-66.

3. Song JM, Kim SD, Kim JH, Kim MJ, Kang DH, Seo JB, et al. Long-term predictors of descending aorta aneurysmal change in patients with aortic dissection. JAm Coll Cardiol. 2007;50:799-804.

4. Saitoh Y, Yokoi Y, Soeda T, Yuri K. Endovascular exclusion of a false lumen associated with residual dissection after proximal aortic repair using a custom-made false lumen occluder. J Thorac Cardiovasc Surg. 2016;152: e41-3.

5. Ogawa Y, Nishimaki H, Chiba K, Murakami K, Sakurai Y, Fujiwara K, et al. Candy-plug technique using an excluder aortic extender for distal occlusion of a large false lumen aneurysm in chronic aortic dissection. J Endovasc Ther. 2016; 23:483-6.

6. Falkenberg M, Roos H, Lepore V, Svensson G, Zachrisson K, Henrickson O et al. Endovascular closure of chronic dissection entries in the aortic arch using the Amplatzer vascular plug II as a sealing button. J Endovasc Ther. 2016;23: 378-83. 